\title{
Non-coding RNAs Associated with Prader-Willi Syndrome Regulate Transcription of Neurodevelopmental Genes in Human Induced Pluripotent Stem Cells
}

\author{
Monika Sledziowska ${ }^{1}$, Matt Jones ${ }^{2}$, Ruba Al Maghrabi ${ }^{3}$, Daniel Hebenstreit ${ }^{2}$, Paloma \\ Garcia $^{3,4}$ and Pawel Grzechnik ${ }^{1,4}$
}

1 School of Biosciences, University of Birmingham, Edgbaston, Birmingham, B15 2TT, UK 2 School of Life Sciences, Gibbet Hill Campus, University of Warwick, Coventry, CV4 7AL, UK 3 School of Medical Sciences, University of Birmingham, Edgbaston, Birmingham, B15 2TT, UK 4 Birmingham Centre for Genome Biology, University of Birmingham, Edgbaston, Birmingham, B15 2TT, UK

Correspondence: P.L.Grzechnik@bham.ac.uk

Keywords: Prader-Willi syndrome, human induced pluripotent cells, chromatin-associated RNA, neurodevelopment 
bioRxiv preprint doi: https://doi.org/10.1101/2021.05.11.443612; this version posted May 11, 2021. The copyright holder for this preprint

(which was not certified by peer review) is the author/funder, who has granted bioRxiv a license to display the preprint in perpetuity. It is made available under aCC-BY-NC-ND 4.0 International license.

\section{ABSTRACT:}

Mutations and aberrant gene expression during cellular differentiation lead to neurodevelopmental disorders such as Prader-Willi syndrome (PWS) which results from the deletion of an imprinted locus on chromosome 15. We analysed chromatin-associated RNA in human induced pluripotent cells (iPSCs) upon depletion of hybrid small nucleolar long non-coding RNAs (sno-IncRNAs) and 5' snoRNA capped and polyadenylated long non-coding RNAs (SPA-IncRNAs) transcribed from the locus deleted in PWS. We found that rapid ablation of these IncRNAs affects transcription of specific gene classes. Downregulated genes contribute to neurodevelopment and neuronal maintenance while genes that are upregulated are predominantly involved in the negative regulation of cellular metabolism and apoptotic processes. Our data revealed the importance of SPA-IncRNAs and sno-IncRNAs in controlling gene expression in iPSCs and provided a platform for synthetic experimental approaches in PWS studies. We conclude that ncRNAs transcribed from the PWS locus are critical regulators of a transcriptional signature important for neuronal differentiation and development. 


\section{INTRODUCTION}

Prader-Willi syndrome (PWS) is a genetic neurodevelopmental disorder characterised by hypotonia in infancy, developmental delay, cognitive disability, behavioural problems and hyperphagia often leading to life-threatening obesity (Angulo et al., 2015). The cause of PWS is the lack of expression of genes from the paternally inherited locus q11-q13 on chromosome 15. This can occur as a result of a paternal deletion in the $15 q 11-q 13$ region ( $70 \%$ of cases), maternal uniparental disomy $(20-30 \%$ of cases) or imprinting defect (1\% of cases) (Cheon, 2016). Post-mortem analysis of hypothalamic tissue of patients with PWS revealed upregulation of genes signalling hunger and downregulation of genes which regulate feeding (Bochukova et al., 2018). Moreover, genes involved in neurogenesis, neurotransmitter release and synaptic plasticity were downregulated in those patients, while microglial genes associated with inflammatory responses were excessively expressed (Bochukova et al., 2018). The molecular processes resulting in this misregulation of gene expression are yet to be determined.

The PWS locus encodes the SNURF-SNRPN, NDN, MKRN3, NAPAP1, and MAGEL2 genes. SNURF-SNRPN 3' untranslated region extends into the non-coding region called SNGH14. The introns of SNGH14 contain multiple clusters of box C/D small nucleolar RNAs (snoRNAs) (Qi et al., 2017). Both SNURF-SNRPN and SNHG14 share the same promoter and exons. The minimal deletion associated with PWS spans $118 \mathrm{~kb}$ in SNHG14 and encompasses twenty-nine copies of snoRNA SNORD116 and a single snoRNA, SNORD119A (Bieth et al., 2015). Box C/D snoRNAs are short (60-300 nucleotides) ncRNAs that form ribonucleoprotein complexes and mediate ribose 2'-O-methylation of predominantly ribosomal RNA (rRNA) and small nuclear RNAs (snRNAs) (Kufel and Grzechnik, 2019). These snoRNAs contain guiding sequences which are complementary to their RNA targets. However, the majority of snoRNAs in humans do not possess a clear affinity to any cellular RNA sequences and thus are called orphan snoRNAs. These snoRNAs may act on multiple RNA targets or play other undetermined roles in the cell. Similarly, snoRNAs encoded from the 15q11-q13 locus are also orphan snoRNAs and their functions remain largely unknown.

Recent studies showed that some snoRNAs from the locus missing in PWS can form two types of hybrid long non-coding RNAs (IncRNA): five small nucleolar RNA related long non-coding RNAs (sno-IncRNAs) and two 5' snoRNA capped and polyadenylated IncRNA (SPA-IncRNAs) (Figure 1A) (Wu et al., 2016; Yin et al., 2012). Both sno-IncRNAs and SPA-IncRNAs are by-products of SNURFSNRPN-SNGH14 processing (Wu et al., 2016; Yin et al., 2012). Sno-IncRNAs are formed by two snoRNA embedded into the same intron which when spliced out is degraded by 3'-5' and 5'-3' exonucleases. Intron degradation continues until it is blocked by the snoRNA that defines the $3^{\prime}$ ' and 5' ends of sno-IncRNAs. Thus, each of the five sno-IncRNAs consists of an intervening sequence flanked by two snoRNAs at each end, all arising from the same intron of the SNHG14 ncRNA. The 5' ends of the two SPA-IncRNAs in the PWS locus coincide with SNORD107 (SPA1-IncRNA) and SNORD109A (SPA2-InCRNA), while the 3' end is polyadenylated. SPA-IncRNA formation is associated with the degradation of RNA downstream of poly(A) sites (PAS). Following endonucleolytic cleavage, the RNA is degraded by the 5'-3' exonuclease until it reaches a snoRNA sequence. This generates the 5 ' end of SPA-IncRNAs and allows for Polymerase II to continue elongation to another PAS in the sequence that defines the 3' end of SPA-IncRNAs. The intervening regions of sno- and SPA-IncRNAs were shown to 
sequester the RNA processing and splicing factors TDP43, RBFOX2, hnRNP M and hence affect alternative splicing (Wu et al., 2016).

Previous studies of PWS in cellular models focused primarily on changes in total RNA (Bochukova et al., 2018; McCann and Baserga, 2012; Zahova et al., 2021), which reflects the levels of cytoplasmic steady-state RNA. We examined the possibility that the ablation of sno-IncRNAs and SPAIncRNAs from the 15q11-q13 locus affects the nascent transcriptome. Since this is usually not detectable in total RNA, which depends largely on transcript stability, we examined chromatinassociated RNA (chRNA) that reflects active nascent transcription across the genome. Acute depletion of sno- and SPA-IncRNA in human induced pluripotent stem cells (iPSCs) revealed their role in the regulation of transcription of neuronal genes. These observations provide an insight into a possible molecular mechanism by which deletion in the 15q11-q13 region affects neuronal differentiation and thus gives rise to the cognitive and behavioural symptoms occurring in PWS.

\section{RESULTS}

\section{SPA-IncRNAs and sno-IncRNAs accumulate at high levels in iPSCs}

SPA- and sno-IncRNAs were initially described in human embryonic $\mathrm{H} 9$ line and teratocarcinoma PA1 cells (Wu et al., 2016; Yin et al., 2012). Since PWS is a neurodevelopmental disease, we chose human induced pluripotent cells (iPSCs) as our model to investigate the impact of PWS-related ncRNAs on gene expression in undifferentiated cells. We employed RT-qPCR analysis to determine if SPA- and sno-IncRNAs were expressed in the iPSC (CREM003i-BU3C2) line reprogrammed from a blood sample of a 40 year old human male (Park et al., 2017) and HEK293T and HeLa cell lines derived from human embryonic kidney and cervical cancer cells, respectively. While SPA- and sno-IncRNAs were abundantly expressed in iPSCs, they were barely detectable in either HEK293T or HeLa cells (Figure 1B). This is consistent with previous report indicating that these RNAs are abundant in stem cells but not in non-pluripotent cells (Wu et al., 2016; Yin et al., 2012). Given with this observation, we confirmed iPSCs as a model suitable for PWS research.

SPA- and sno-IncRNAs are localised close to their transcription sites (Wu et al., 2016; Yin et al., 2012). Thus, we tested if these ncRNAs were bound to the chromatin in iPSCs by performing chromatin-associated RNA sequencing (chRNA-seq). We first extracted nuclei, then separated the soluble fraction and the insoluble chromatin pellet, which retains tightly associated transcription factors and chromatin-associated RNAs, including newly synthesised and nascent RNA (Figure 1C). In parallel, from intact cells, we isolated total RNA, which is dominated by steady-state, cytoplasmic RNA. Both fractions were prepared in biological duplicates and sequenced on the lllumina platform. The fractionation procedure in iPSCs was successful, the chromatin RNA fraction showed a clear increase in intronic to exonic reads ratio, indicative of the efficient removal of steady-state RNA (Figure S1A). In the total RNA fraction, we found that RNAs from SNHG14 locus, encompassing the SPA- and snoIncRNAs, were one of the most abundant transcripts on chromosome 15, followed by two mRNAs encoding ribosomal proteins RPL4 and RPS17. In the chromatin fraction, transcripts from SNHG14 were the dominant RNAs from chromosome 15 (Figure 1D). In particular, sno-IncRNA3 and snoIncRNA4 were the most abundant in both total, and chromatin-associated RNA. This was in contrast to 
data from H9 cells where SPA-IncRNAs were one the most highly expressed ncRNAs from the PWS locus only second to SNURF-SNRPN mRNA (Wu et al., 2016).

This observation prompted us to test the overall cellular abundance of PWS ncRNAs in iPSCs. We calculated transcript per million (TPM) values for total RNA and chromatin-associated RNA samples and ranked transcripts by their expression level (Figure 1E). In total RNA, containing mostly cytoplasmic RNAs, SNHG14 was within $14 \%$ of the top expressed genes (ranked on $86^{\text {th }}$ percentile), higher than ubiquitously transcribed IncRNA NEAT1 $\left(65^{\text {th }}\right.$ percentile). SNURF-SNRPN mRNA was ranked on $58^{\text {th }}$ percentile. One of the most abundant RNAs in the total RNA fraction were MALAT1 and GAPDH (ranked on $98^{\text {th }}$ and $99^{\text {th }}$ percentile, respectively), confirming the accuracy of our analysis. In the chromatin-associated fraction SNHG14 transcripts ascended to the top $4 \%$ (96 ${ }^{\text {th }}$ percentile) most abundant RNAs and were ranked higher than pluripotency factor NANOG and NEAT1 (both ranked on $91^{\text {st }}$ percentile) (Figure $1 \mathrm{E}$ ). Similar to the total RNA fraction, SNURF-SNRPN chromatin-associated mRNA was ranked much lower than SNHG14 RNA. Discrepancies in mRNA levels between the two fractions, for example for GAPDH $\left(99^{\text {th }}\right.$ and $65^{\text {th }}$ in total and chromatin-associated RNA, respectively) reflect the fact that mRNA levels in the cell are maintained not only by RNA synthesis but also by RNA stability (Singh et al., 2019). When we analysed sno-IncRNA3 and sno-IncRNA4 only, these RNAs were ranked in top $2 \%$ and $1 \%$ of expressed transcripts in total and chromatin-associated RNA respectively, as seen for MALAT1. Such high levels indicate that RNAs transcribed from SNHG14 may play essential roles in iPSCs.

Our analysis of RNA fractions in iPSCs revealed that almost all PWS ncRNAs were clearly detected in both the total and chromatin-associated RNA fractions, with the exception of SPA1-IncRNA, which was less abundant in the total RNA fraction than other transcripts (Figure 1D). Moreover, we detected increased reads spanning from position +41 of exon 23 to the PWAR6 element of SNHG14, within the boundaries of the SPA1-InCRNA (Figure 1F). This suggests the presence of a previously unannotated ncRNA, which we term 'inside-of-SPA1-IncRNA' (inSPA1), that may arise from 5'-3' degradation of SPA1-IncRNA if the exonucleases are blocked by RNA structures further downstream. Computational prediction using Vfold and mfold software revealed that the 5' end of inSPA1-IncRNA, containing exon 23 and its 41 upstream nucleotides, indeed folds into a number of stem-loops that may be able to block exonucleolytic trimming (Figure 1F).

\section{Antisense oligonucleotides-dependent depletion of PWS transcripts}

Fast depletion approaches provide an opportunity to investigate the direct effects of how the reduced RNAs act in cellular pathways. To determine the effect of an acute ablation of SPA- and snoIncRNAs on the transcriptome, we employed antisense oligonucleotides (AOS) GapmeRs (Qiagen), which targeted IncRNAs and triggered RNA cleavage by endogenous RNaseH and the subsequent degradation by exoribonucleases. We designed a panel of GapmeRs against the individual PWS ncRNAs (Figure 2A) targeting their intervening sequences located in-between terminal snoRNAs or poly $(A)$ tail. To compare the effect of the different types of ncRNAs on transcription we used three sets of GapmeRs against: 1) all seven sno/SPA-IncRNAs, 2) five sno-IncRNAs, and 3) two SPA-IncRNAs. These were compared with a negative control, where iPSCs were treated with an equivalent amount of 
non-specific GapmeRs. Since some of SNHG14 ncRNAs overlap, the GapmeR against SPA2-IncRNA was designed not to affect any sequences contained within sno-IncRNAs. However, all GapmeRs against sno-IncRNAs also targeted SPA2-IncRNA.

We nucleofected iPSCs with each set of GapmeRs and isolated total and chromatin-associated fractions after 24 hours. RT-qPCR performed on total RNA revealed efficient knockdown of all seven IncRNA species using GapmeRs set 1 (SPA/sno-IncRNAs KD) (Figure 2B). However, in cells transfected with set 2 (sno-IncRNAs KD) both sno-IncRNAs and SPA2-IncRNA were knocked down. Set 3 (SPA-IncRNAs KD) knocked down SPA1-IncRNA; however, SPA2-IncRNA was only partially affected. Overall, we achieved a knockdown up to $60-80 \%$ of the selected RNA species across the different sets. We also tested the efficiency of GapmeRs by quantifying chromatin-associated SNHG14 ncRNAs via chRNA-seq upon GapmeR nucleofection (Figure 2C). Our data revealed that GapmeRs set 1 efficiently reduced accumulation of SPA1-IncRNA (and putative inSPA1), SPA2-IncRNA and all 5 sno-IncRNAs. GapmeRs set 2 decreased sno-IncRNAs and SPA2- but not SPA1-IncRNA, while set 3 mainly affected SPA1-InCRNA and to a lesser extent SPA2- and sno-IncRNAs. Interestingly, GapmeRsdependent knockdown was still detectable for some RNAs after 5 days from nucleofection (Figure S1B), demonstrating the utility of this system in longer experimental setups. Overall, we showed that GapmeRs can be used as an easy-to-employ alternative to genomic deletions in PWS studies.

\section{SPA- and sno-IncRNAs regulate transcription of neuronal genes}

We analysed how rapid depletion of SPA- and sno-IncRNAs affected RNA levels in iPSCs. We did not detect global effects on the steady-state transcriptome in iPSCs nucleofected with GapmeRs set 3 targeting all PWS IncRNAs (Figure S2A). Previous studies revealed that genes regulating neuronal processes and genes contributing to immune response were affected in post-mortem hypothalamic tissue of patients with PWS (Bochukova et al., 2018). However, it is not clear what process drives this deregulation. Since many non-coding RNAs control transcription of protein-coding genes (Werner and Ruthenburg, 2015), next we tested levels of chromatin-associated RNAs upon SPA- and sno-IncRNAs knockdowns.

Our chRNA-seq performed on cells treated with GapmeRs sets for 24 hours uncovered the impact of ncRNAs on transcription of protein-coding genes (Figure $3 A$ ). We used differential gene expression analysis to compare SPA/sno-IncRNAs KD (set 1), sno-IncRNAs KD (set 2) and SPAIncRNAs KD (set 3) with a control treated with non-specific GapmeRs, all in two biological repeats. We observed the greatest alterations in RNA levels between SPA/sno-IncRNAs KD and control conditions, with 205 downregulated and 87 upregulated transcripts. The differences observed between the remaining two conditions and control were more subtle, which is consistent with the varied efficiency of the GapmeR sets in depletion of PWS ncRNAs. Among the top ten most significantly downregulated genes in SPA/sno-IncRNAs KD were FAT3, NRXN1, NLGN1 and SNHG14 confirming the efficiency of the knockdown in this condition (Figure 3A-B and S2B). The three other top downregulated genes are involved in the regulation of neuronal development and function; FAT3 is a cadherin which determines the polarity of developing neurons by regulating the interactions between neurites (Deans et al., 2011), while NLGN1 and NRXN1 are membrane adhesion proteins, which have the capacity to bind to each 
other across a synapse. NLGN1 induces the formation of presynaptic boutons allowing for neuron maturation (Wittenmayer et al., 2009), and NRXN1 regulates neuronal development, function and synaptic transmission (Uchigashima et al., 2020; Zhang et al., 2018). The comparison between snoIncRNAs KD and control rendered only 2 downregulated genes: FAT3 and NRXN1, while the SPAIncRNAs KD failed to produce any significant changes in transcription (Figure $3 A$ ).

Interestingly, among the top ten most significant genes upregulated by SPA/sno-IncRNAs KD were genes that negatively affect proliferation and differentiation, or contribute to neuronal function: CDKN1A, JDP2, CHAC1 and TRIB3 (Figure 3B and S2B). CDKN1A negatively affects cellular proliferation by binding to and inhibiting cyclin-dependent kinases activities (Al Bitar and Gali-Muhtasib, 2019; Kreis et al., 2019). JDP2 is involved in transcriptional responses associated with transcription factor AP-1, such as induced apoptosis and cell differentiation (Kim et al., 2010). CHAC1 inhibits Notch signalling to promote neuronal differentiation, while TRIB3 is an inactive kinase that plays a role in programmed neuronal cell death (Jin et al., 2002; Ohoka et al., 2005). Two other knockdowns of snoIncRNAs and SPA-IncRNAs (set 2 and 3) did not result in transcriptional upregulation for any genes (Figure $3 \mathrm{~A}$ ). Consistent with the results of differential expression analysis, hierarchical clustering correctly grouped the duplicates of the SPA/sno-IncRNAs KD, sno-IncRNAs KD and control samples. The SPA-IncRNAs KD samples duplicates did not cluster well, which may be the result of less efficient and variable knockdowns (Figure S3A).

Active transcription of genes involved in neuronal differentiation in iPSCs was somewhat unexpected. Thus, we sought to confirm the stem status of the CREM003i-BU3C2 cell line and tested for the presence of actively transcribed neuronal markers. We calculated the abundance of transcripts in chromatin-associated RNA isolated from cells nucleofected with control GapmeRs. Transcription of proliferation markers including POU5F1, NANOG, and SFRP2 was evident in the chRNA-seq data (Figure $3 \mathrm{C}$ and Table S1). Markers of both immature neurons (e.g. NEUROD1, NCAM1, DCX) and mature neurons (e.g. ENO2, MAP2 TUBB3, NEFL) were detected to a lesser extent in the chromatinassociated RNA fraction, and markers for functional neurons (e.g. CHAT, TH, GAD2) were virtually absent. A similar trend was observed in the total RNA fraction (Figure S3B and Table S1). Moreover, the accumulation of mRNA of genes involved in neurodevelopment NRXN1, NLGN1 and FAT3 in total RNA fraction was significantly lower than in the chromatin-associated RNA samples, which was the opposite pattern observed for constitutively expressed gene GAPDH (Figure 3D). This indicates that genes involved in neurodevelopment were transcribed but their mRNAs did not accumulate in nondifferentiating iPSCs.

We observed the most significant differences in chromatin-associated RNA upon combined SPA/sno-IncRNAs depletion thus, we focused on exploring the functions of differentially expressed genes in this condition only. We employed Gene Ontology (GO) terms analysis to identify the relevant pathways. The genes whose transcription was downregulated by the SPA- and sno-IncRNAs knockdown are involved in pathways related to neuronal development, function and cell adhesion (Figure $3 \mathrm{E}$ ), which is consistent with the decreased levels of FAT1, NRXN1 and NLGN1 in this condition (Figure 3B). These pathways include maintenance of membrane integrity, glutamatergic synapses ( $P$ $<0.001)$, synaptic membranes $(P<0.001)$, and synapse assembly processes $(P<0.001)$. Genes which 
were upregulated by the SPA- and sno-IncRNAs knockdown participate in the dampening of cellular growth and proliferation as well as in promoting apoptosis, including regulation of cellular protein metabolic processes, apoptotic processes, and programmed cell death $(P<0.001)$. This is consistent with transcriptional upregulation of CDKN1A, TRIB3 and JDP2 in this knockdown (Figure 3B).

To complement the GO analysis, we employed Gene Set Enrichment Analysis. The input for this analysis consisted of all detected transcripts, which allowed for identifying small, coordinated changes that would not otherwise be recognised (Subramanian et al., 2005). These transcripts were then ranked based on the $\log _{2}$ fold change which allowed for the determination of a wide range of activated or suppressed pathways (Figure 4A). The results of this analysis were consistent with the GO results, revealing pathways associated with central nervous system development $(P<0.001)$ were among those supressed upon SPA/sno-IncRNAs knockdown. This method allowed us to identify a number of other affected pathways, which were not evident from GO analysis. We found that SPA- and sno-IncRNAs depletion also suppresses pathways associated with intracellular and cell-cell signalling (correlated with terms "enzyme linked receptor protein signalling pathway" and "endosome"), as well as processes linked to immune processes (terms "leukocyte activation", "immune effector process"), which is consistent with the misregulation of immune system genes observed in PWS (Bochukova et al., 2018). We further identified a group of activated pathways that are involved in hormonal regulation. However, these pathways included fewer genes and were associated with higher p-values than supressed pathways. Genes identified in the top five most significant pathways were visualised as cnetplot (Figure 4B). Interestingly, the genes contributing to the suppressed pathways that regulate the development of the central nervous system included SHANK2 and CNTNAP2, deletions of which are associated with autism and intellectual disability (Berkel et al., 2010; Canali et al., 2018). Overall, our analyses indicate that the lack of ncRNAs transcribed from the locus deleted in PWS deregulates a broad spectrum of pathways that may contribute to aberrant development of the structures in the human brain.

\section{DISCUSSION}

The molecular basis of the neurodevelopmental genetic disorder Prader-Willi syndrome remains largely unknown. We depleted SPA-IncRNAs and sno-IncRNAs transcribed from the 15q11q13 locus deleted in PWS to study their impact on transcription in human iPSCs. Our analysis of chromatin-associated RNA shows that the lack of these ncRNAs decreased transcription of neurodevelopmental genes and increased transcription of factors that negatively affect cellular growth and mediate apoptosis. The region downstream of the SNURF-SNRPN gene, SNHG14, that encompasses the minimal deletion resulting in PWS (Sahoo et al., 2008), produces one of the most abundant chromatin-associated RNAs in iPSCs (Figure 1). This is consistent with previous reports showing that SPA- and sno-IncRNAs levels are among the most highly expressed IncRNAs in embryonic H9 cells (Wu et al., 2016; Yin et al., 2012). The chromatin association of PWS ncRNAs points towards their possible function in transcription regulation; approximately $60 \%$ of IncRNAs display a strong bias for the chromatin association and play roles in the activation of neighbouring or distant genes (Werner and Ruthenburg, 2015). 
SPA- and sno-IncRNAs display unique structural properties: the snoRNA structures at 5' or both ends make them relatively resistant to prevalent exonucleolytic activities. Thus the intervening sequence can be used as a sponge RNA to sequester transcription and splicing factors TDP43, RBFOX2, hnRNP $M$ and hence affect gene expression via regulation of alternative splicing (Wu et al., 2016; Yin et al., 2012). Our analysis of chromatin-associated RNA, that can be used as a proxy for active transcription of protein-coding genes (Mayer et al., 2015), uncovered that SPA- and sno-IncRNAs control the transcription of many genes that regulate neurodevelopment including $N R X N 1, N L G N 1$, and FAT3. We found that SPA- and sno-IncRNAs depletion decreased transcription levels for many genes that contribute to the formation of neuron specific structures - axons and synapses, as well as genes required for proper cell adhesion and cell-cell signalling (Figure 3 and 4). Interestingly, a significant population of genes which were upregulated by SPA- and sno-IncRNAs knockdown, are involved in the negative regulation of cellular metabolism and apoptosis. One possible explanation of this phenotype is that misregulation of neurodevelopmental genes that may result in abnormal differentiation is countered by repression of cell growth and ultimately, cell death. Indeed, neurons developed from iPSCs that model neurodevelopmental diseases including Fredreich ataxia and spinal muscular atrophy are more prone to senescence and apoptosis (Igoillo-Esteve et al., 2015; Ohashi et al., 2018). We cannot exclude the possibility that this regulation is directly provided by the factors that bind to SPAand sno-IncRNAs however, it is more plausible that these proteins control alternative splicing of other transcriptional factors governing transcription of neuronal genes.

Interestingly, genes involved in neuron maturation and maintenance such as NRXN1, NLGN1, or FAT3 were detected in the chromatin-associated fraction, indicating their active transcription (Figure 3A-B). However, their presence was not reflected at similar levels in the steady-state RNA population (Figure 3D). The accumulation of cytoplasmic RNAs may be buffered by degradation pathways that downregulate excessive transcription (Singh et al., 2019). Keeping genes that contribute to cell differentiation in the "on" state may facilitate quick transitions during development. We speculate that the transcriptional activation of genes required for neuronal development primes their efficient expression when necessary.

The global effect of SPA- and sno-IncRNAs depletion on RNA levels was completely lost in the total RNA fraction, representing mainly steady-state cytoplasmic RNAs (Figure S2A). This is consistent with the observation in a mouse model where only seven genes including transcription factor Mafa and growth suppressor Necdin were upregulated by deletions in PWS locus (Zahova et al., 2021). In human cells, deregulation of transcription caused by the absence of SPA- and sno-IncRNAs may feature in total RNA levels in later stages of neurodevelopment, when the expression of these genes is essential to support neuronal maturation. Moreover, adjusting mRNA to optimal concentration in dynamically differentiating stem cells, when the gene transcription is affected, may not be as responsive and efficient as in healthy cells. Thus, it may introduce errors in gene expression that accumulate during development and, as a consequence, manifest as PWS. Such a pathological pattern, where a transcriptional regulation imbalance emerges already in stem cells, impacts neuronal development and results in a late onset disease, has been reported for many neurodevelopmental disorders including Fragile $X$ and Rett syndromes as well as neurodegenerative Alzheimer's and Huntington's diseases 
(Sabitha et al., 2021; Sorek et al., 2021). Mild but persistent effects on overall gene expression may be the reason why the deletions in the PWS locus are not lethal. However, as neurons progress through highly organised processes of differentiation, migration and functional activation, any disruption in gene expression may affect the development of human brain, leading to the manifestation of neurodevelopmental disorders.

\section{ACKNOWLEDGMENTS}

This work was funded by a grant from Foundation for Prader-Willi Research (FPWR). M.S. was supported by FPWR, DH is funded by EPSRC (grant EP/T002794/1), BBSRC (grants BB/L006340/1 and BB/M017982/1); MJ is supported by Midlands Doctoral Training Partnership for a studentship to M.J. funded by BBSRC BB/M01116X/1. R.A. was funded by the Royal Embassy of Saudi Arabia Cultural Bureau and Saudi Arabia Ministry of Higher Education. P.Grz. was supported by a Sir Henry Dale Fellowship from the Wellcome Trust and the Royal Society (200473/Z/16/Z). We thank George Murphy for sharing the iPSC line. We thank Kinga Kamieniarz-Gdula and Holly Fagarasan for critical reading of the manuscript and Genomics Birmingham at the University of Birmingham for assistance with NGS.

\section{AUTHOR CONTRIBUTION}

M.S. performed experimental part of this study. M.S., M.J. and D.H. analysed the sequencing data. R.H. and P.G. assisted with iPSCs culturing. M.S., P.G. and P.Grz. design the experiments. M.S. and P.Grz. wrote the manuscript. P.Grz. conceived the project. 

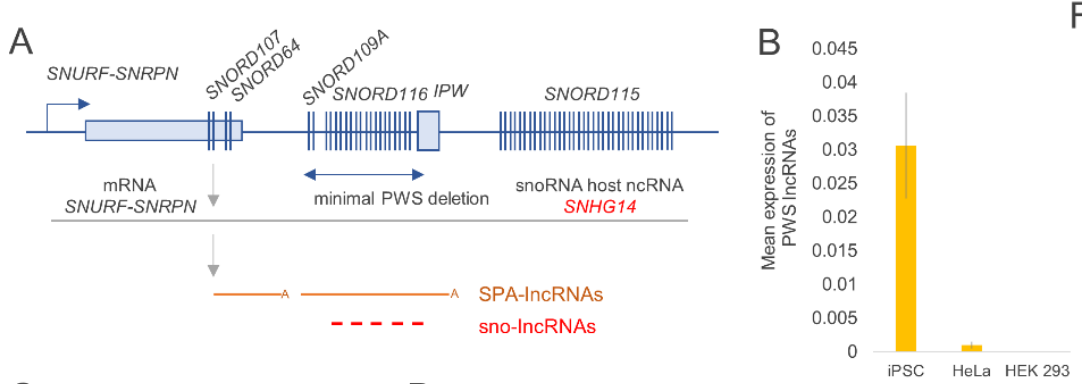

Fig. 1

C
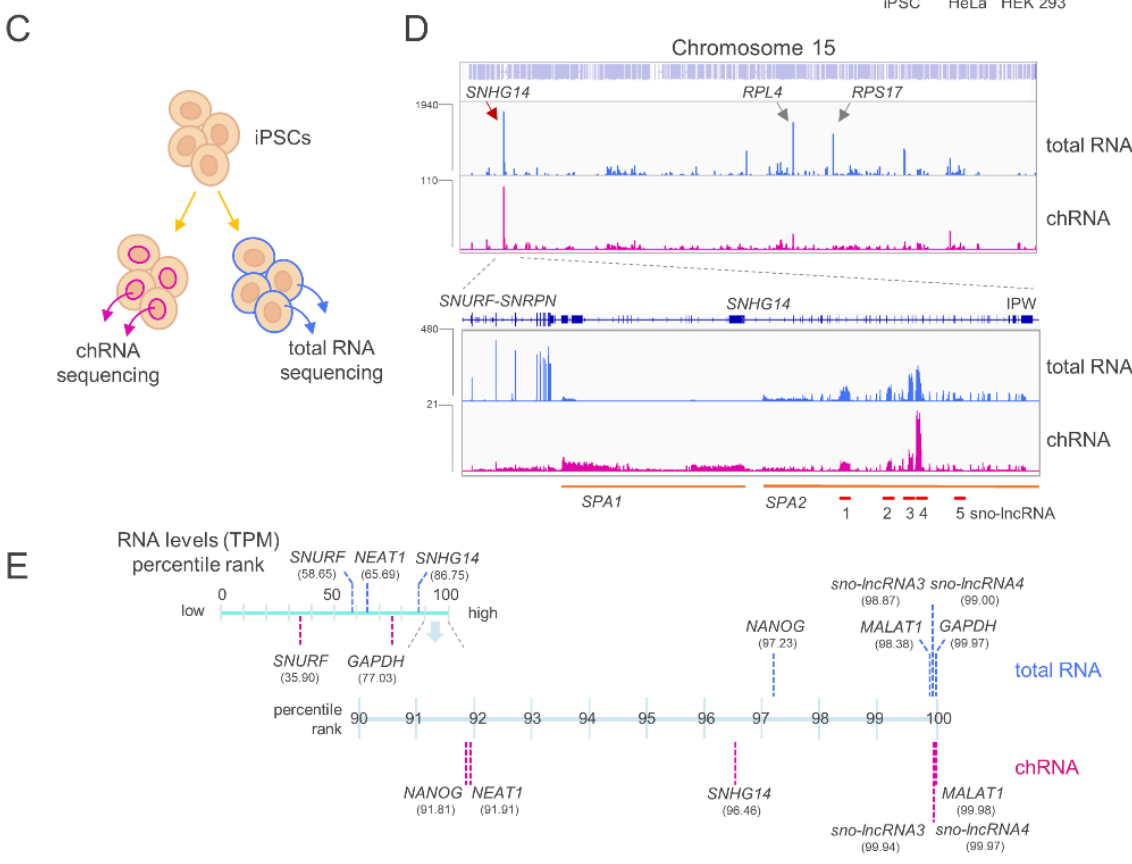

$\mathrm{F}$

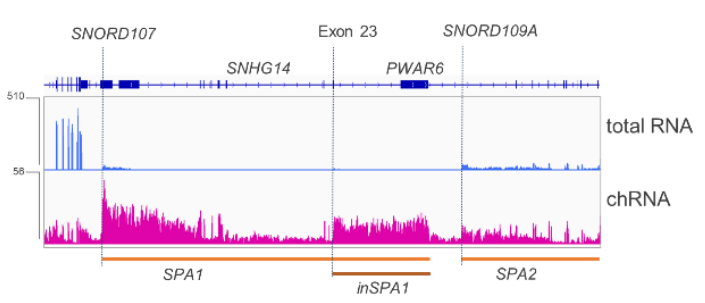

G

Figure 1. Accumulation of PWS-related ncRNAs on the chromatin in iPSCs. (A) Diagram showing organization of IncRNAs transcribed downstream of SNURF-SNRPN gene. SNORD - snoRNA genes, $I P W$ - imprinted gene in the Prader-Willi syndrome region. (B) Accumulated expression of PWS IncRNAs in IPSCs, HEK293T and HeLa cells relative to the house-keeping gene GAPDH. The average of three biological experiments is shown, error bars indicate standard error. (C) The experimental approach used in the study. RNA was isolated either from the whole cell (total RNA) or from the insoluble nuclear fraction (chromatin-associated RNA). (D) Distribution of total RNA (blue) and chromatin-associated RNA (purple) on chromosome 15. Locations of SPA-IncRNAs and sno-IncRNAs are shown below the track; chRNA-seq analysis. (E) The abundance of RNAs in iPSCs in total RNA and chromatin-associated RNA fractions are shown for selected genes as a percentile rank. (F) Distribution of chRNA-seq reads indicating the position of putative additional IncRNA (inSPA1). (G) Secondary RNA structure of exon 23 revealed by Vfold and mfold predictions. chRNA-seq tracks shows counts $\times 10^{6}$; chRNA - chromatin-associated RNA; TPM - transcript per million. 
A
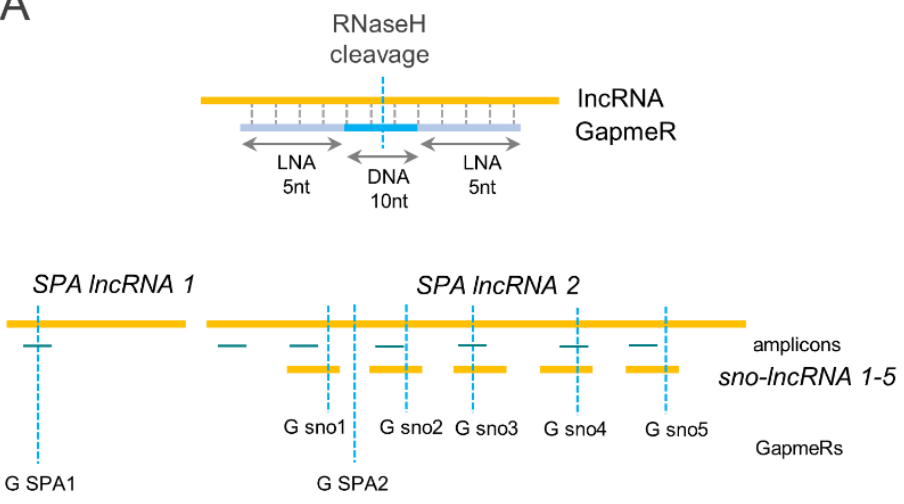

B

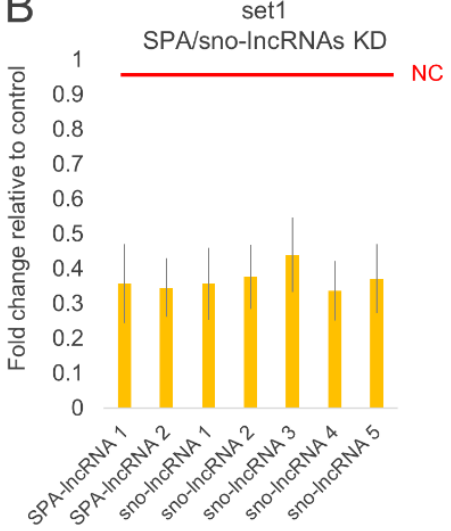

set2

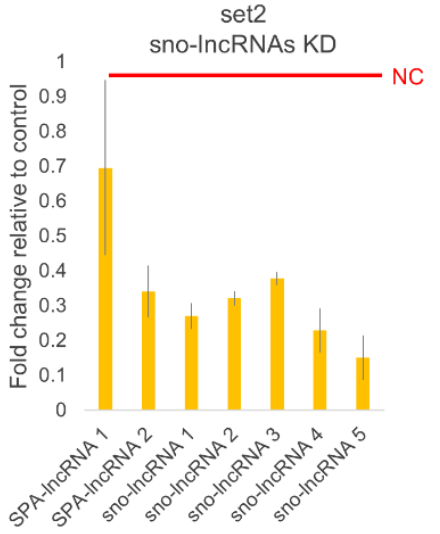

Fig. 2

iPSCs

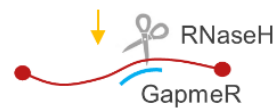

chRNA

sequencing

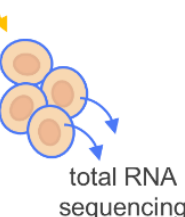

set3

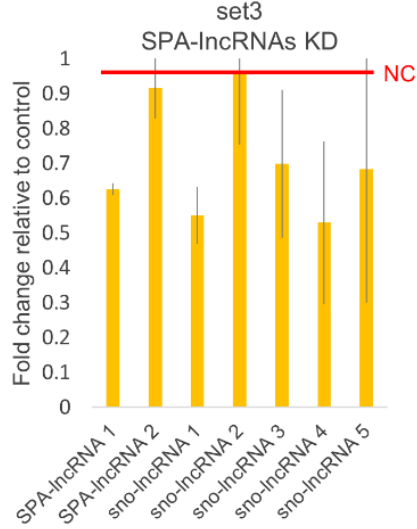

UBE3A

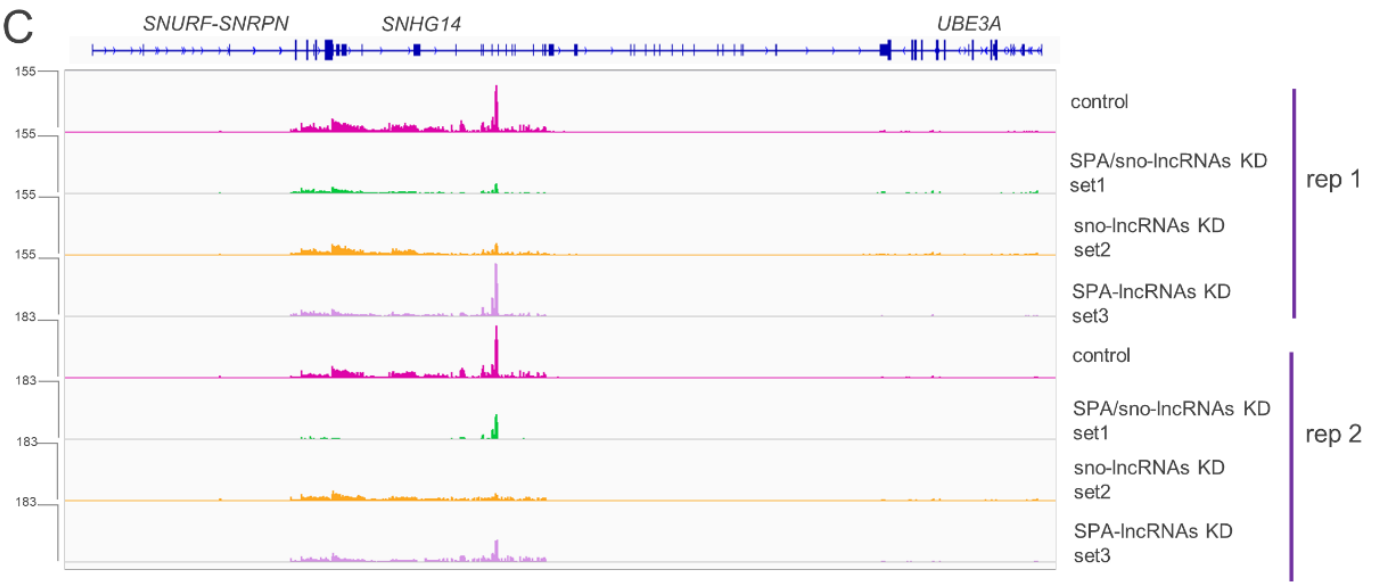

Figure 2. Antisense oligonucleotides mediate efficient knockdown of SPA- and sno-IncRNAs.

(A) The locations of GapmeRs (vertical blue lines denoted G) targeting SPA- and sno-IncRNAs and qPCR amplicons (horizontal green lines) used in the study. Note the overlap of sno-IncRNAs and SPA2IncRNA. A diagram depicting the experimental design is shown on right. (B) Fold change relative to negative control (red line) in SPA- and sno-IncRNAs levels 24h post introduction of GapmeRs into iPSCs. qPCR analysis showing an average of three independent experiments, error bars correspond to standard error. (C) chRNA-seq reads from SPA- sno-IncRNAs host gene SNHG14 in iPSCs treated with different sets of GapmeRs. Rep -replicate. chRNA-seq tracks shows counts $\times 10^{6}$. 
A

SPA/sno-InCRNAS KD vs NC

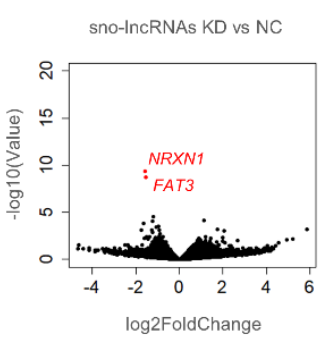

Fig. 3
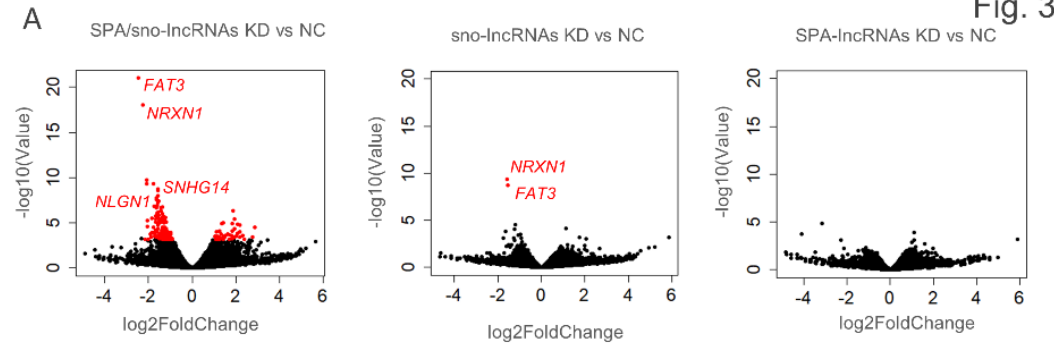

B
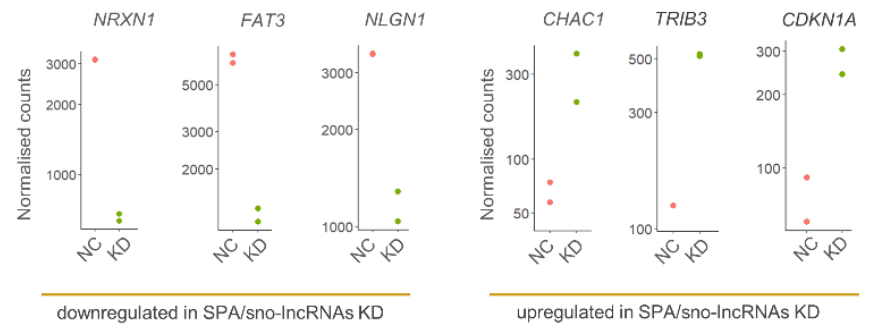

C

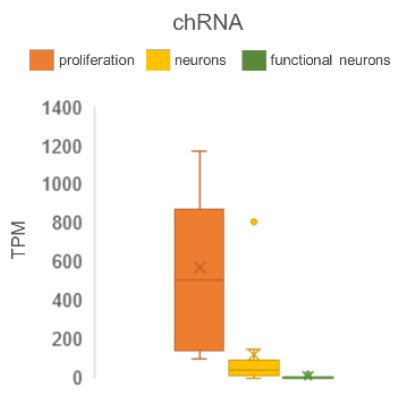

D
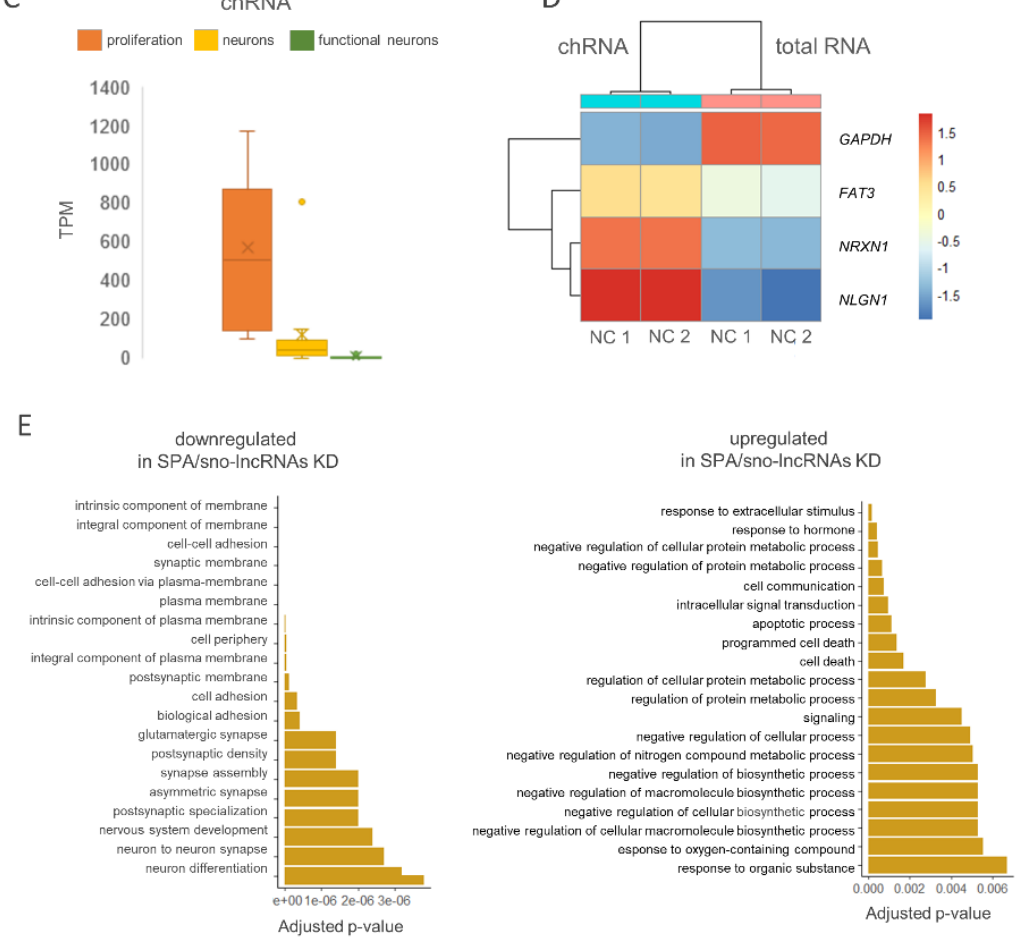

Figure 3. Depletion of SPA- and sno-IncRNAs affects the accumulation of chromatin-associated RNA in iPSCs. (A) Differentially accumulated chromatin-associated RNAs (in red) between the control (NC - nonspecific GapmeRs control) and SPA/sno-IncRNAs knockdown (KD) combinations. Volcano plots showing results of two biological replicates of chRNA-seq for each sample. (B) Normalised counts for genes selected from the top ten either down- or upregulated genes in chRNA-seq analysis of SPA/sno-IncRNAs depletion. (C) Transcript per million (TPM) values for markers associated with proliferation, immature, mature and functional neurons in chromatin-associated RNA fraction in iPSCs. (D) Heatmap showing the expression of neuronal and control genes in total RNA and chromatinassociated RNA fractions in iPSCs. (E) Go terms associated with downregulated and upregulated genes in chRNA-seq datasets. chRNA- chromatin-associated RNA 
bioRxiv preprint doi: https://doi.org/10.1101/2021.05.11.443612; this version posted May 11, 2021. The copyright holder for this preprint (which was not certified by peer review) is the author/funder, who has granted bioRxiv a license to display the preprint in perpetuity. It is made available under aCC-BY-NC-ND 4.0 International license.

Fig. 4

A

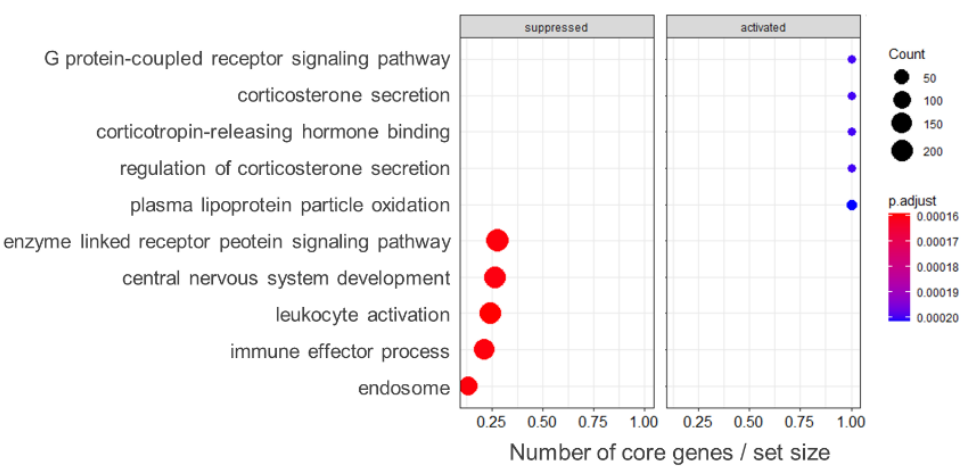

B

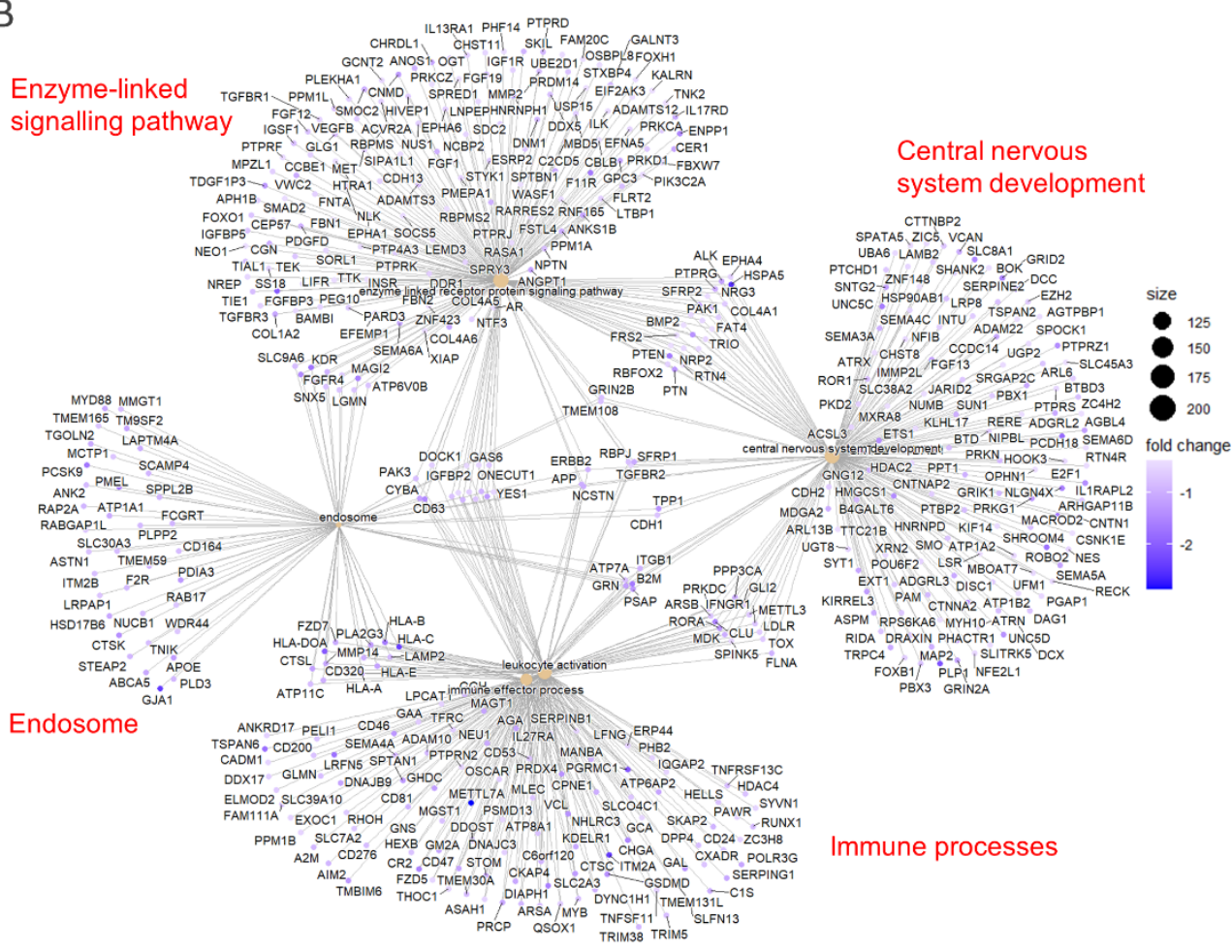

Figure 4. SPA- and sno-IncRNAs impact multiple pathways in iPSCs (A) Activated and suppressed pathways indicated by changes in chromatin-associated RNA fractions. (B) Cnetplot showing genes participating in the top five supressed pathways by SPA- and sno-IncRNAs knockdown. 
bioRxiv preprint doi: https://doi.org/10.1101/2021.05.11.443612; this version posted May $11,2021$. The copyright holder for this preprint (which was not certified by peer review) is the author/funder, who has granted bioRxiv a license to display the preprint in perpetuity. It is made available under aCC-BY-NC-ND 4.0 International license.

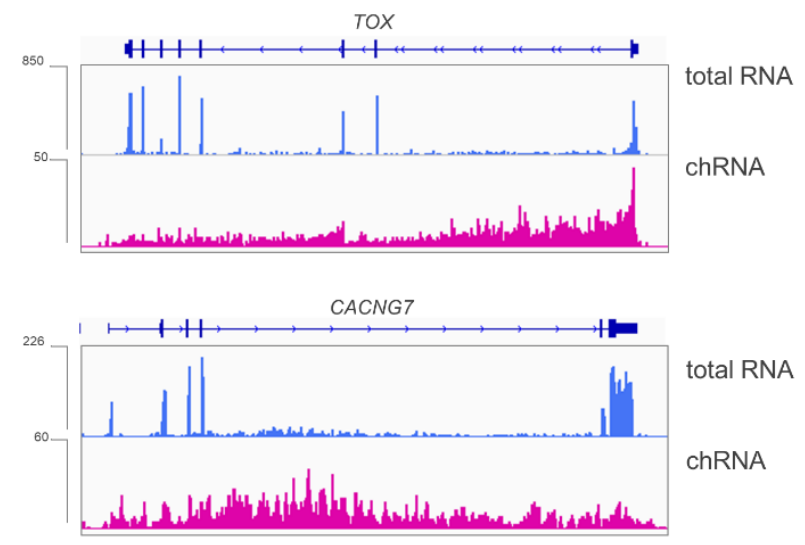

B

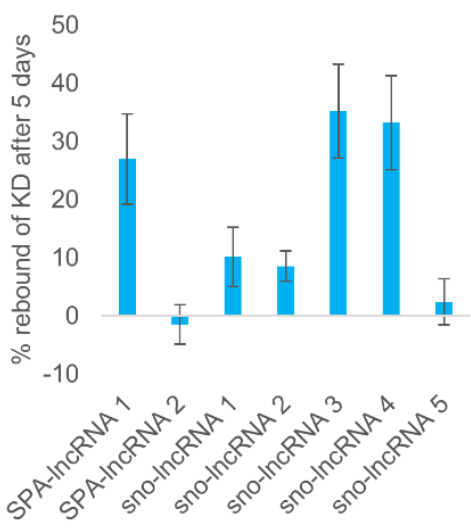

Figure S1. (A) Reads for TOX and CACNG7 in total and chromatin-associated RNA (chRNA) samples showing enrichment of reads in the intronic regions, characteristic for samples containing nascent RNA. chRNA-seq analysis. (B) Percentage increase in expression of sno/SPA-IncRNAs between $24 \mathrm{~h}$ and 5 days post knockdown. RT-qPCR analysis. chRNA-seq track shows counts $\times 10^{6}$. 
bioRxiv preprint doi: https://doi.org/10.1101/2021.05.11.443612; this version posted May $11,2021$. The copyright holder for this preprint (which was not certified by peer review) is the author/funder, who has granted bioRxiv a license to display the preprint in perpetuity. It is made available under aCC-BY-NC-ND 4.0 International license.

Fig. S2

A

Total RNA

SPA/sno-IncRNAs KD vs NC

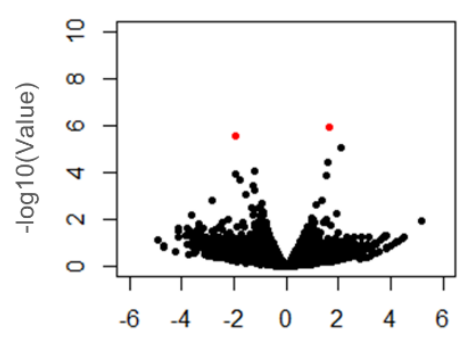

log2FoldChange

B

downregulated in SPA/sno-IncRNAs KD

upregulated in SPA/sno-IncRNAs KD
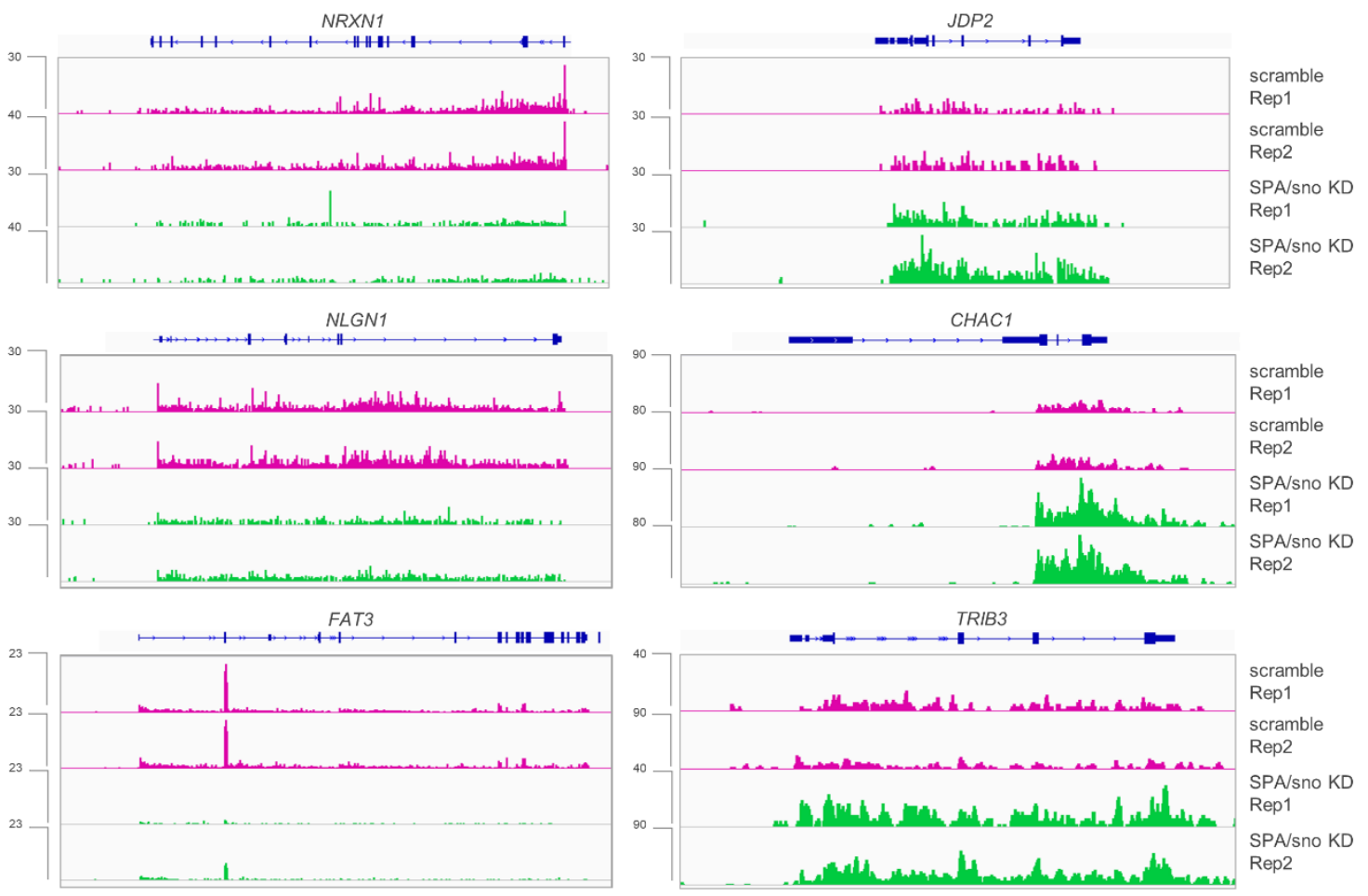

Figure S2. (A) Volcano plot showing differentially expressed genes (red) between control and SPA/snoIncRNAs knockdown in total RNA fraction. (B) chRNA-seq reads for the top downregulated genes in SPA/sno-IncRNAs KD and control. (C) chRNA-seq reads for the top upregulated genes in SPA/snoIncRNAs KD and control. chRNA-seq track shows counts $\times 10^{6}$. 
bioRxiv preprint doi: https://doi.org/10.1101/2021.05.11.443612; this version posted May 11,2021 . The copyright holder for this preprint (which was not certified by peer review) is the author/funder, who has granted bioRxiv a license to display the preprint in perpetuity. It is made available under aCC-BY-NC-ND 4.0 International license.

Fig. S3

A

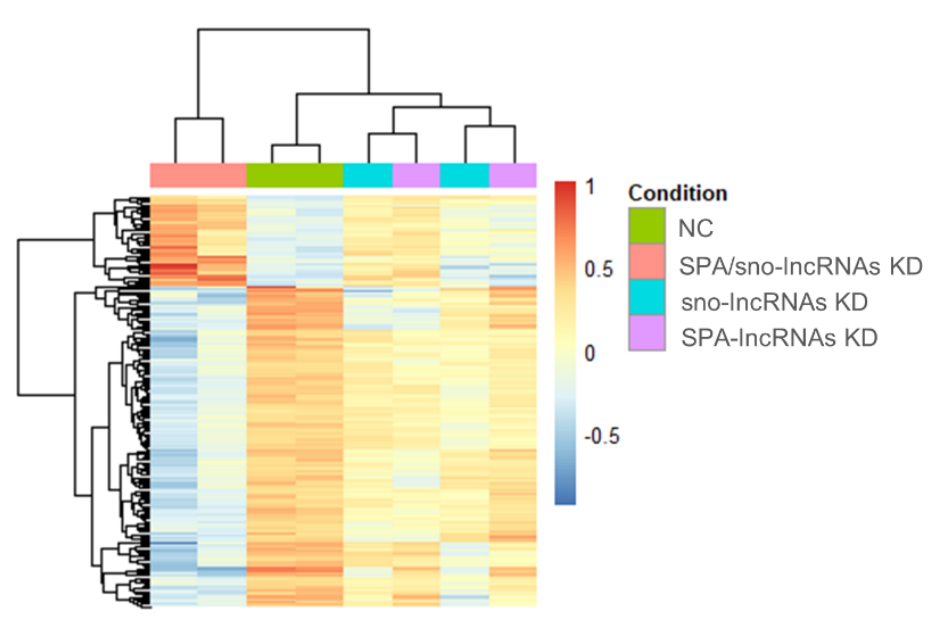

B

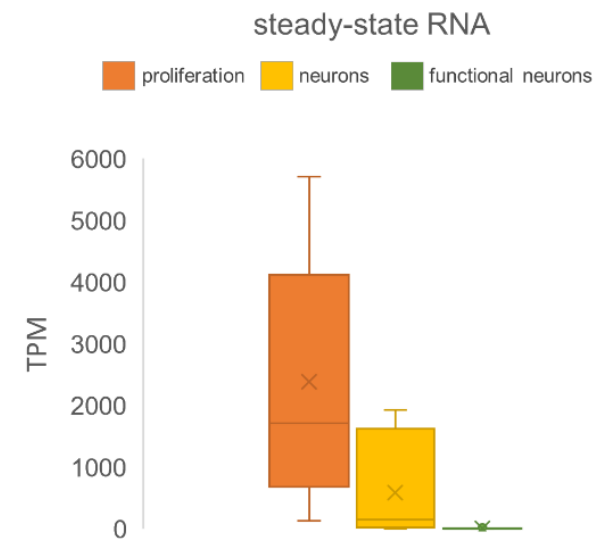

Figure S3. (A) Heatmap of all of the differentially expressed genes between sno/SPA-IncRNAs KD and control in chRNA-seq. Note correct clustering between the sno/SPA-IncRNAs and control samples. (B) Transcript per million (TPM) values for markers associated with proliferation, immature, mature and functional neurons in control total RNA samples. 
bioRxiv preprint doi: https://doi.org/10.1101/2021.05.11.443612; this version posted May 11, 2021. The copyright holder for this preprint (which was not certified by peer review) is the author/funder, who has granted bioRxiv a license to display the preprint in perpetuity. It is made available under aCC-BY-NC-ND 4.0 International license.

\begin{tabular}{lll} 
Proliferation & Neurons & Functional neurons \\
\hline POU5F1 & NEUROD1 & CHAT \\
NANOG & NCAM1 & TH \\
CNMD & DCX & GAD2 \\
USP44 & ENO2 & SLC17A7 \\
VSNL1 & MAP2 & SLC17A6 \\
CRABP1 & TUBB3 & FEV \\
& NEFL & \\
& NEFM & \\
& NEFH &
\end{tabular}

Table S1. Proliferation, neurons and functional neurons markers. 


\title{
METHODS
}

\section{RESOURCE AVAILABILITY}

Lead contact

Further information and requests for resources and reagents should be directed to and will be fulfilled by the lead contact, Pawel Grzechnik (p.l.grzechnik@bham.ac.uk).

\author{
Materials availability \\ This study did not generate new unique reagents. \\ Data and code availability \\ The dataset generated during this study are available at GEO (GSE174043).
}

\section{EXPERIMENTAL MODEL AND SUBJECT DETAILS}

Human iPSC line CREM003i-BU3C2 (Park et al., 2017) originating from a blood samples of a 40 year old human male, was kept at $36^{\circ} \mathrm{C}$ and $0.5 \% \mathrm{CO}_{2}$. The cells were cultured in 6-well plates coated with Matrigel (Corning), with StemFlex medium (Gibco) supplemented with Primocin (InvovGen). The media was changed $48 \mathrm{~h}$ after a passage and then every $24 \mathrm{~h}$. Cells were passaged using STEMPRO EZPassage tool (ThermoFisher Scientific) when 70-80\% confluent. HEK293T and HeLa transformed cell lines derived from human embryonic kidney and cervical cancer cells respectively. Both were cultured at $36^{\circ} \mathrm{C}$ and $0.5 \% \mathrm{CO}_{2}$, in $10 \mathrm{~cm}$ plates, with DMEM medium (Gibco) supplemented with $10 \%$ FBS and Penicillin-Streptomycin antibiotics mixture. Media was changed every 3-4 days.

\section{METHOD DETAILS}

GapmeR design

Antisense oligonucleotides (GapmeRs) were designed using QIAGEN online tool with intervening sequences of SPA- and sno-IncRNAs as input. GapmeRs for each ncRNA were selected based on the QIAGEN's design score and they were synthesised by QIAGEN.

\section{Gapmer-mediated knockdown}

Confluent iPSCs were treated with $1 \mathrm{ml}$ of TrypLE (Gibco) per well in 6-well plates in order to obtain a single-cell suspension. Cells were incubated for 2 min at $36^{\circ} \mathrm{C}$ when TrypLE was removed, and then cells were placed back at $36^{\circ} \mathrm{C}$ for another $3 \mathrm{~min}$. $1 \mathrm{ml}$ of DPBS (Gibco) was added to each well and the cells were collected and centrifuged at $200 \mathrm{~g}$ for $5 \mathrm{~min}$. The supernatant was removed and the cells were resuspended in $100 \mu \mathrm{L}$ of nucleofector solution from P3 Primary Cell 4D-Nucleofector Kit (Lonza) per transfection. The cells were then divided into individual nucleofection cuvettes, and the appropriate mixture of GapmeRs were added, 6 uL of each. Approximately $2 \times 10^{6}$ cells were utilised per transfection. The transfections were performed using 4D-Nucleofector (Lonza) using setting DS-150. Following the nucleofection the cuvettes were incubated at $36^{\circ} \mathrm{C}$ for $5 \mathrm{~min}$, then transferred to $1 \mu \mathrm{L}$ of StemFlex medium and incubated at $36^{\circ} \mathrm{C}$ for another $10 \mathrm{~min}$. The cells were plated on a Matrigel-coated 6 -well plate, cells from every nucleofection were equally divided between the 6 wells in a plate. The cells were then cultured using standard conditions detailed above for $24 \mathrm{~h}$ after which they were collected for RNA extraction.

\section{RNA extraction and fractionation}

The cells were with $1 \mathrm{ml}$ of TrypLE (Gibco) per well in a 6-well plates in order to obtain a single-cell suspension. The cells were incubated for $5 \mathrm{~min}$ at $36^{\circ} \mathrm{C}$ or until they detached, at which point $2 \mathrm{~mL}$ of DPBS was added per well. The cells were collected and centrifuged at $200 \mathrm{~g}$ for $5 \mathrm{~min}$. The supernatant was removed and the cells were either resuspended in $1 \mathrm{~mL}$ of TRIZOL (ThermoFisher Scientific) for total RNA extraction or in $200 \mu \mathrm{L}$ of Cytoplasmic Lysis Buffer (0.15\% NP-40, $10 \mathrm{mM}$ Tris- $\mathrm{HCl} \mathrm{pH}$ 7, 150 $\mathrm{mM} \mathrm{NaCl}, 50 \mathrm{U}$ RiboLock) for chRNA fractionation.

For chRNA fractionation, samples were incubated for 5 min on ice in the Cytoplasmic Lysis Buffer, after which they were layered on $500 \mu \mathrm{L}$ of Sucrose Buffer $(10 \mathrm{mM}$ Tris- $\mathrm{HCl} \mathrm{pH} 7,150 \mathrm{mM} \mathrm{NaCl}, 25 \%$ Sucrose, $50 \mathrm{U}$ RiboLock). Nuclei were collected by centrifugation of $16000 \mathrm{~g}$ for $10 \mathrm{~min}$ at $4^{\circ} \mathrm{C}$. The supernatant containing cytoplasmic fraction was then removed, and nuclei were washed with Nuclei Wash Buffer (PBS supplemented with 0.1\% Triton X-100, 1 mM EDTA, 50 U RiboLock) at $1200 \mathrm{~g}$ for 1 
min at $4^{\circ} \mathrm{C}$. The supernatant was discarded and the nuclei were resuspended in $200 \mu \mathrm{L}$ of Glycerol Buffer (20 mM Tris- $\mathrm{HCl} \mathrm{pH} \mathrm{8,} 75 \mathrm{mM} \mathrm{NaCl}, 0.5 \mathrm{mM}$ EDTA, $50 \%$ glycerol, $0.85 \mathrm{mM}$ DTT, 50 U RiboLock). Next $200 \mu \mathrm{L}$ of Nuclei Lysis Buffer (1\% NP-40, $20 \mathrm{mM}$ HEPES pH 7.5, $300 \mathrm{mM} \mathrm{NaCl}, 1 \mathrm{M}$ Urea, 0.2 mM EDTA, $1 \mathrm{mM}$ DTT, $50 \cup$ RiboLock) was mixed with samples by pulsed vortexing for $2 \mathrm{~min}$, and centrifuged at $18500 \mathrm{~g}$ for $2 \mathrm{~min}$ at $4^{\circ} \mathrm{C}$. The pellet containing chRNA was resuspended in $200 \mu \mathrm{L}$ of PBS supplemented with $50 \mathrm{U}$ RiboLock. Following resuspension, $500 \mu \mathrm{L}$ of TRIZOL was added and the samples were vortexed.

At this point, for both total RNA and chRNA samples, $100 \mu \mathrm{L}$ of chloroform was added and the samples were incubated at room temperature for $5 \mathrm{~min}$. The samples were then centrifuged at $16000 \mathrm{~g}$ for 15 min at $4^{\circ} \mathrm{C}$. The samples were then processed using RNeasy kit (QIAGEN), following the "RNA cleanup" protocol enclosed with the kit. The samples were then quantified using NanoDrop spectrometer and gDNA contamination was removed using TURBO DNA-free Kit (ThermoFisher Scientific) according to the manufacturer's instructions. The samples were stored at $-80^{\circ} \mathrm{C}$ until they were further processed for RT-PCR or RNA sequencing.

$R T-q P C R$

The gDNA-depleted RNA samples were reverse transcribed using SuperScript III Reverse Transcriptase (ThermoFisher Scientific). Briefly, $500-2000 \mathrm{ng}$ of RNA were diluted up to $11 \mu \mathrm{L}$ of RNAse-free water, combined with $1 \mu \mathrm{L}$ of Random Hexamer Primers (Thermofisher Scientific) and 1 $\mu \mathrm{L}$ of $10 \mathrm{mM}$ dNTPs and incubated at $65^{\circ} \mathrm{C}$ for $5 \mathrm{~min}$. Following the incubation the samples were briefly placed on ice, and $4 \mu \mathrm{L}$ of SuperScript III Reverse Transcriptase buffer (Thermofisher Scientific), $2 \mu \mathrm{L}$ of DTT, $8 \mathrm{U}$ of RiboLock and $1 \mu \mathrm{L}$ of SuperScript III Reverse Transcriptase were added per sample. The samples were incubated at $25{ }^{\circ} \mathrm{C}$ for $10 \mathrm{~min}$, at $50{ }^{\circ} \mathrm{C}$ for $40 \mathrm{~min}$ and at $82{ }^{\circ} \mathrm{C}$ for $5 \mathrm{~min}$ in a thermocycler.

For RT-qPCR, the cDNA samples were diluted 1:10. For each $15 \mu \mathrm{L}$ reaction, $7.5 \mu \mathrm{L}$ of $2 \mathrm{X}$ SyGreen Mix (PCRBio), $0.8 \mu \mathrm{L}$ of each $10 \mu \mathrm{M}$ primer, $0.9 \mu \mathrm{L}$ of PCR grade water and $5 \mu \mathrm{L}$ of diluted cDNA were mixed. Three reactions per sample and per set of primers were prepared and processed using RotoGene (QIAGEN) with standard cycling.

\section{RNA sequencing}

Prior to RNA sequencing, total RNA samples were rRNA depleted using RiboCop (Lexogen) according to manufacturer's instructions. Samples were re-quantified using Qubit (Thermofisher Scientific), and up to $100 \mathrm{ng}$ of RNA was used for library preparation using NEBNext Ultra II RNA Library Prep Kit for Illumina (NEB). The libraries were prepared according to manufacturer's instructions, quantified and quality checked using TapeStation (Agilent). The libraries were prepared with indexing primers and pooled into 2 library preps. There were 8 chRNA libraries that were pooled together and sequenced on a single G NextSeq 500/550 (150) flow cell to obtain sequencing depth of approximately 40M reads per sample. The 4 total RNA libraries were pooled with another 8 libraries not analysed here; the 12 libraries were then loaded and sequenced on another G NextSeq 500/550 (150) flow cell resulting in a lower sequencing depth. The RNA sequencing was performed at the Genomics Facility at the University of Birmingham. Briefly, the concentrations of the libraries were determined using Qubit and the average library size was determined using TapeStation (Agilent). The libraries were then diluted to $1.6 \mathrm{pM}$, and $1 \%$ of $20 \mathrm{pM}$ PhiX control were added. The libraries were then loaded onto a flow cell and the sequencing was performed on Illumina NEXTseq.

\section{Quantification and statistical analysis}

Data quality control was performed with FastQC v0.11.5 (Andrews, 2010), and aligned with STAR v2.5.3a (Dobin et al., 2013) to the human genome (GRCh38.p10, Gencode comprehensive annotation). RNA-seq reads were aligned with parameters; --outSAMtype BAM SortedByCoordinate. The counts per gene were calculated with LiBiNorm v2.4 (Dyer et al., 2019), in HTseq-count (Anders et al., 2015) compatible mode with parameters; --htseq-compatible --order pos, --stranded no, --type gene, --idattr gene_name. Count per million normalised bigwig files were constructed using deeptools (Ramírez et al., 2016) bamcompare with parameters; --binSize 15, --normalizeUsing CPM. Once raw counts were extracted the data was analysed in $\mathrm{R}$ (version 4.0.5). Differential expression analysis was performed using DESeq2 package. A gene was considered differentially expressed when the adjusted $p$-value 
bioRxiv preprint doi: https://doi.org/10.1101/2021.05.11.443612; this version posted May 11, 2021. The copyright holder for this preprint (which was not certified by peer review) is the author/funder, who has granted bioRxiv a license to display the preprint in perpetuity. It is made available under aCC-BY-NC-ND 4.0 International license.

was smaller than 0.1 which is a standard setting for this package. The set of differentially expressed genes was then used as input for the GO analysis, which was executed using topGO package. All of the detected genes were used as input for GSEA analysis which was done using clusterProfiler package. 


\section{REFERENCES}

Anders, S., Pyl, P.T., and Huber, W. (2015). HTSeq-a Python framework to work with highthroughput sequencing data. Bioinformatics 31, 166-169.

Andrews, S. (2010). FastQC: A Quality Control Tool for High Throughput Sequence Data [Online]. Available online at: http://www.bioinformatics.babraham.ac.uk/projects/fastqc/.

Angulo, M.A., Butler, M.G., and Cataletto, M.E. (2015). Prader-Willi syndrome: A review of clinical, genetic, and endocrine findings. J. Endocrinol. Invest. 38, 1249-1263.

Berkel, S., Marshall, C.R., Weiss, B., Howe, J., Roeth, R., Moog, U., Endris, V., Roberts, W., Szatmari, P., Pinto, D., et al. (2010). Mutations in the SHANK2 synaptic scaffolding gene in autism spectrum disorder and mental retardation. Nat. Genet. 42, 489-491.

Bieth, E., Eddiry, S., Gaston, V., Lorenzini, F., Buffet, A., Conte Auriol, F., Molinas, C., Cailley, D., Rooryck, C., Arveiler, B., et al. (2015). Highly restricted deletion of the SNORD116 region is implicated in Prader-Willi syndrome. Eur. J. Hum. Genet. 23, 252-255.

Al Bitar, S., and Gali-Muhtasib, H. (2019). The Role of the Cyclin Dependent Kinase Inhibitor p21(cip1/waf1) in Targeting Cancer: Molecular Mechanisms and Novel Therapeutics. Cancers (Basel). 11, 1475.

Bochukova, E.G., Lawler, K., Croizier, S., Keogh, J.M., Patel, N., Strohbehn, G., Lo, K.K., Humphrey, J., Hokken-Koelega, A., Damen, L., et al. (2018). A Transcriptomic Signature of the Hypothalamic Response to Fasting and BDNF Deficiency in Prader-Willi Syndrome. Cell Rep. 22, 3401-3408.

Canali, G., Garcia, M., Hivert, B., Pinatel, D., Goullancourt, A., Oguievetskaia, K., Saint-Martin, M., Girault, J.-A., Faivre-Sarrailh, C., and Goutebroze, L. (2018). Genetic variants in autism-related CNTNAP2 impair axonal growth of cortical neurons. Hum. Mol. Genet. 27, 1941-1954.

Cheon, C.K. (2016). Genetics of prader-willi syndrome and prader-will-like syndrome. Ann. Pediatr. Endocrinol. Metab. 21, 126-135.

Deans, M.R., Krol, A., Abraira, V.E., Copley, C.O., Tucker, A.F., and Goodrich, L. V. (2011). Control of neuronal morphology by the atypical cadherin fat3. Neuron 71, 820-832.

Dobin, A., Davis, C.A., Schlesinger, F., Drenkow, J., Zaleski, C., Jha, S., Batut, P., Chaisson, M., and Gingeras, T.R. (2013). STAR: ultrafast universal RNA-seq aligner. Bioinformatics 29, 15-21.

Dyer, N.P., Shahrezaei, V., and Hebenstreit, D. (2019). LiBiNorm: an htseq-count analogue with improved normalisation of Smart-seq2 data and library preparation diagnostics. PeerJ 7, e6222.

Igoillo-Esteve, M., Gurgul-Convey, E., Hu, A., Romagueira Bichara Dos Santos, L., Abdulkarim, B., Chintawar, S., Marselli, L., Marchetti, P., Jonas, J.-C., Eizirik, D.L., et al. (2015). Unveiling a common mechanism of apoptosis in $\beta$-cells and neurons in Friedreich's ataxia. Hum. Mol. Genet. 24, 22742286.

Jin, C., Li, H., Murata, T., Sun, K., Horikoshi, M., Chiu, R., and Yokoyama, K.K. (2002). JDP2, a Repressor of AP-1, Recruits a Histone Deacetylase 3 Complex To Inhibit the Retinoic Acid-Induced Differentiation of F9 Cells. Mol. Cell. Biol. 22, 4815 LP - 4826.

Kim, K.-H., Jeong, J.-Y., Surh, Y.-J., and Kim, K.-W. (2010). Expression of stress-response ATF3 is mediated by Nrf2 in astrocytes. Nucleic Acids Res. 38, 48-59.

Kreis, N.-N., Louwen, F., and Yuan, J. (2019). The Multifaceted p21 (Cip1/Waf1/CDKN1A) in Cell Differentiation, Migration and Cancer Therapy. Cancers (Basel). 11, 1220.

Kufel, J., and Grzechnik, P. (2019). Small Nucleolar RNAs Tell a Different Tale. Trends Genet. 35, 104-117.

Mayer, A., Di lulio, J., Maleri, S., Eser, U., Vierstra, J., Reynolds, A., Sandstrom, R., Stamatoyannopoulos, J.A., and Churchman, L.S. (2015). Native elongating transcript sequencing reveals human transcriptional activity at nucleotide resolution. Cell 161, 541-554.

McCann, K.L., and Baserga, S.J. (2012). Long noncoding RNAs as sinks in Prader-Willi syndrome. 
Mol. Cell 48, 155-157.

Ohashi, M., Korsakova, E., Allen, D., Lee, P., Fu, K., Vargas, B.S., Cinkornpumin, J., Salas, C., Park, J.C., Germanguz, I., et al. (2018). Loss of MECP2 Leads to Activation of P53 and Neuronal Senescence. Stem Cell Reports 10, 1453-1463.

Ohoka, N., Yoshii, S., Hattori, T., Onozaki, K., and Hayashi, H. (2005). TRB3, a novel ER stressinducible gene, is induced via ATF4-CHOP pathway and is involved in cell death. EMBO J. 24, 12431255.

Park, S., Gianotti-Sommer, A., Molina-Estevez, F.J., Vanuytsel, K., Skvir, N., Leung, A., Rozelle, S.S., Shaikho, E.M., Weir, I., Jiang, Z., et al. (2017). A Comprehensive, Ethnically Diverse Library of Sickle Cell Disease-Specific Induced Pluripotent Stem Cells. Stem Cell Reports 8, 1076-1085.

Qi, X., Shao, M., Sun, H., Shen, Y., Meng, D., and Huo, W. (2017). Long non-coding RNA SNHG14 promotes microglia activation by regulating miR-145-5p/PLA2G4A in cerebral infarction. Neuroscience 348, 98-106.

Ramírez, F., Ryan, D.P., Grüning, B., Bhardwaj, V., Kilpert, F., Richter, A.S., Heyne, S., Dündar, F., and Manke, T. (2016). deepTools2: a next generation web server for deep-sequencing data analysis. Nucleic Acids Res. 44, W160-W165.

Sabitha, K.R., Shetty, A.K., and Upadhya, D. (2021). Patient-derived iPSC modeling of rare neurodevelopmental disorders: Molecular pathophysiology and prospective therapies. Neurosci. Biobehav. Rev. 121, 201-219.

Sahoo, T., Del Gaudio, D., German, J.R., Shinawi, M., Peters, S.U., Person, R.E., Garnica, A., Cheung, S.W., and Beaudet, A.L. (2008). Prader-Willi phenotype caused by paternal deficiency for the HBII-85 C/D box small nucleolar RNA cluster. Nat. Genet. 40, 719-721.

Singh, P., James, R.S., Mee, C.J., and Morozov, I.Y. (2019). mRNA levels are buffered upon knockdown of RNA decay and translation factors via adjustment of transcription rates in human HepG2 cells. RNA Biol. 16, 1147-1155.

Sorek, M., Oweis, W., Nissim-Rafinia, M., Maman, M., Simon, S., Hession, C.C., Adiconis, X., Simmons, S.K., Sanjana, N.E., Shi, X., et al. (2021). Pluripotent stem cell-derived models of neurological diseases reveal early transcriptional heterogeneity. Genome Biol. 22, 73.

Subramanian, A., Tamayo, P., Mootha, V.K., Mukherjee, S., Ebert, B.L., Gillette, M.A., Paulovich, A., Pomeroy, S.L., Golub, T.R., Lander, E.S., et al. (2005). Gene set enrichment analysis: A knowledgebased approach for interpreting genome-wide expression profiles. Proc. Natl. Acad. Sci. U. S. A. 102, 15545-15550.

Uchigashima, M., Konno, K., Demchak, E., Cheung, A., Watanabe, T., Keener, D.G., Abe, M., Le, T., Sakimura, K., Sasaoka, T., et al. (2020). Specific Neuroligin3-aNeurexin1 signaling regulates GABAergic synaptic function in mouse hippocampus. Elife 9, 1-31.

Werner, M.S., and Ruthenburg, A.J. (2015). Nuclear Fractionation Reveals Thousands of ChromatinTethered Noncoding RNAs Adjacent to Active Genes. Cell Rep. 12, 1089-1098.

Wittenmayer, N., Körber, C., Liu, H., Kremer, T., Varoqueaux, F., Chapman, E.R., Brose, N., Kuner, T., and Dresbach, T. (2009). Postsynaptic Neuroligin1 regulates presynaptic maturation. Proc. Natl. Acad. Sci. U. S. A. 106, 13564-13569.

Wu, H., Yin, Q.F., Luo, Z., Yao, R.W., Zheng, C.C., Zhang, J., Xiang, J.F., Yang, L., and Chen, L.L. (2016). Unusual Processing Generates SPA LncRNAs that Sequester Multiple RNA Binding Proteins. Mol. Cell 64, 534-548.

Yin, Q.F., Yang, L., Zhang, Y., Xiang, J.F., Wu, Y.W., Carmichael, G.G., and Chen, L.L. (2012). Long Noncoding RNAs with snoRNA Ends. Mol. Cell 48, 219-230.

Zahova, S., Humby, T., Davies, J.R., Morgan, J.E., and Isles, A.R. (2021). Comparison of mouse models reveals the molecular bases for psychotic illness in Prader-Willi syndrome. BioRxiv 2021.01.26.428232. 
bioRxiv preprint doi: https://doi.org/10.1101/2021.05.11.443612; this version posted May 11, 2021. The copyright holder for this preprint (which was not certified by peer review) is the author/funder, who has granted bioRxiv a license to display the preprint in perpetuity. It is made available under aCC-BY-NC-ND 4.0 International license.

Zhang, P., Lu, H., Peixoto, R.T., Pines, M.K., Ge, Y., Oku, S., Siddiqui, T.J., Xie, Y., Wu, W., ArcherHartmann, S., et al. (2018). Heparan Sulfate Organizes Neuronal Synapses through Neurexin Partnerships. Cell 174, 1450-1464.e23. 